\title{
The Structural and Magnetic Properties of Gadolinium Doped $\mathrm{CoFe}_{2} \mathrm{O}_{4}$ Nanoferrites
}

\author{
Qing Lin, ${ }^{1,2}$ Jinpei Lin, ${ }^{1}$ Yun He, ${ }^{1}$ Ruijun Wang, ${ }^{2}$ and Jianghui Dong ${ }^{3}$ \\ ${ }^{1}$ College of Physics and Technology, Guangxi Normal University, Guilin 541004, China \\ ${ }^{2}$ Department of Information Technology, Hainan Medical College, Haikou 571101, China \\ ${ }^{3}$ School of Natural and Built Environments, University of South Australia, Adelaide, SA 5095, Australia \\ Correspondence should be addressed to Yun He; hy@gxnu.edu.cn
}

Received 8 August 2014; Accepted 26 August 2014

Academic Editor: Xinqing Chen

Copyright (C) 2015 Qing Lin et al. This is an open access article distributed under the Creative Commons Attribution License, which permits unrestricted use, distribution, and reproduction in any medium, provided the original work is properly cited.

Gadolinium substituted cobalt ferrite $\mathrm{CoGd}_{x} \mathrm{Fe}_{2-x} \mathrm{O}_{4}(x=0,0.04,0.08)$ powders have been prepared by a sol-gel autocombustion method. XRD results indicate the production of a single cubic phase of ferrites. The lattice parameter increases and the average crystallite size decreases with the substitution of $\mathrm{Gd}^{3+}$ ions. SEM shows that the ferrite powers are nanoparticles. Room temperature Mössbauer spectra of $\mathrm{CoGd}_{x} \mathrm{Fe}_{22-x} \mathrm{O}_{4}$ are two normal Zeeman-split sextets, which display ferrimagnetic behavior. The saturation magnetization decreases and the coercivity increases by the $\mathrm{Gd}^{3+}$ ions.

\section{Introduction}

Cobalt ferrite is a hard magnetic material, and it has moderate saturation magnetization of about $80 \mathrm{emu} / \mathrm{g}$, high coercivity of $5000 \mathrm{Oe}$, high Curie temperature $T_{C}$ of $793.15 \mathrm{~K}\left(520^{\circ} \mathrm{C}\right)$, high anisotropy constant of $2.65 \times 10^{6} \sim 5.1 \times 10^{6} \mathrm{erg} / \mathrm{cm}^{3}$, and high magnetostrictive of $-225 \times 10^{-6}[1,2]$. Moreover, cobalt ferrite exhibits high electromagnetic performance, large magneto-optic effect, excellent chemical stability, and mechanical hardness $[3,4]$. In the materials containing $3 \mathrm{~d}$ transition metals, the magnetism carriers are the electrons from the $3 \mathrm{~d}$ shell that are considered to migrate from one atom to another. In rare earth (RE) metals, the magnetism carriers are the $4 \mathrm{f}$ electrons which are protected by the $5 s^{2} 5 p^{6}$ shells, so their magnetic moments are well localized at individual atoms [5-7]. Small amounts of RE element gadolinium can affect the magnetic properties and the magnetic coercivity of Co ferrites. Peng et al. [8] and Rana et al. [9] investigated the effect of $\mathrm{Gd}^{3+}$ substitution on dielectric properties and saturation magnetization of nanocobalt ferrite.

In this paper, nanoferrites $\operatorname{CoGd}_{x} \mathrm{Fe}_{2-x} \mathrm{O}_{4}(x=0,0.04$, 0.08 ) were prepared by a sol-gel autocombustion method. The aim of this study is to investigate variation structural and magnetic properties of cobalt ferrite powders by replacement of small amounts gadolinium.

\section{Experimental}

2.1. Sample Preparation. RE ions substituted cobalt ferrite $\mathrm{CoGd}_{x} \mathrm{Fe}_{2-x} \mathrm{O}_{4}(x=0,0.04,0.08)$ powders were prepared by a sol-gel autocombustion method. The analytical grades $\mathrm{Co}\left(\mathrm{NO}_{3}\right)_{2} \cdot 6 \mathrm{H}_{2} \mathrm{O}, \mathrm{Fe}\left(\mathrm{NO}_{3}\right)_{3} \cdot 9 \mathrm{H}_{2} \mathrm{O}, \mathrm{Gd}\left(\mathrm{NO}_{3}\right)_{3} \cdot 6 \mathrm{H}_{2} \mathrm{O}$, citric acid $\left(\mathrm{C}_{6} \mathrm{H}_{8} \mathrm{O}_{7} \cdot \mathrm{H}_{2} \mathrm{O}\right)$, and ammonia $\left(\mathrm{NH}_{3} \cdot \mathrm{H}_{2} \mathrm{O}\right)$ were used as raw materials. The molar ratio of metal nitrates to citric acid was taken as $1: 1$. The metal nitrates and citric acid were, respectively, dissolved into deionized water to form solution. Ammonia was added to the solution of metal nitrates to change the $\mathrm{pH}$ value from 7 to 9 . The mixed solution was poured into a thermostat water bath and heated at $80^{\circ} \mathrm{C}$ under constant stirring to transform into a dried gel [9]. Citric acid was dropped continually in the process of heating. The gel was dried at $120^{\circ} \mathrm{C}$ in a dry-oven for $2 \mathrm{~h}$, being ignited in the air at room temperature, and the dried gel burnt in a self-propagating combustion way to form loose powder. The powder was ground and annealed at temperatures $800^{\circ} \mathrm{C}$ for $3 \mathrm{~h}$. 


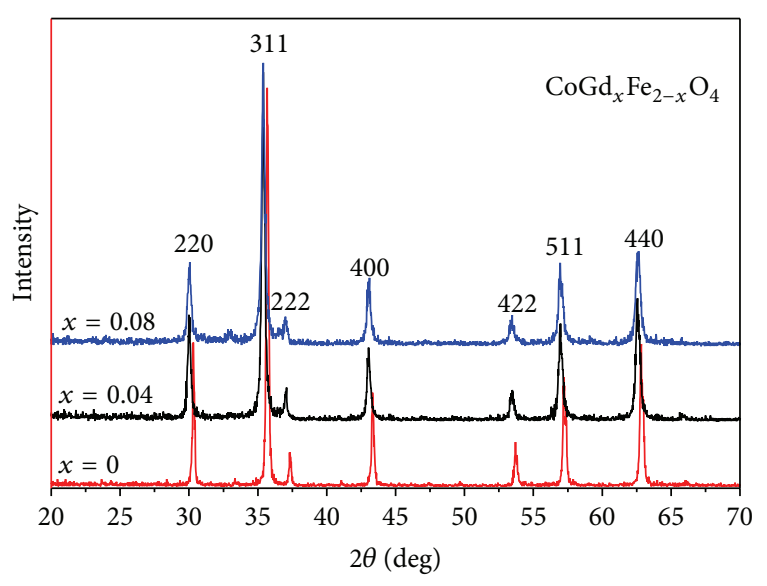

FIgURE 1: Room temperature X-ray diffraction patterns of $\mathrm{CoGd}_{x} \mathrm{Fe}_{2-x} \mathrm{O}_{4}(x=0,0.04,0.08)$ annealed at $800^{\circ} \mathrm{C}$.

TABLE 1: Lattice parameters, average crystallite size, and X-ray densities date of $\mathrm{CoGd}_{x} \mathrm{Fe}_{2-x} \mathrm{O}_{4}(x=0,0.04,0.08)$ ferrites annealed at $800^{\circ} \mathrm{C}$.

\begin{tabular}{lccc}
\hline $\begin{array}{l}\text { Sample } \\
(x)\end{array}$ & $\begin{array}{c}\text { Lattice } \\
\text { parameter } \\
(\AA)\end{array}$ & $\begin{array}{c}\text { Average } \\
\text { crystallite } \\
\text { size }(\AA)\end{array}$ & $\begin{array}{c}\text { Density } \\
\left(\mathrm{g} \cdot \mathrm{cm}^{-3}\right)\end{array}$ \\
\hline 0 & 8.35497 & 556 & 5.3468 \\
0.04 & 8.39787 & 343 & 5.3536 \\
0.08 & 8.39755 & 316 & 5.4452 \\
\hline
\end{tabular}

2.2. Characterization. The crystalline structure was investigated by X-ray diffraction (Rigaku D/max- 2500V/PC) with $\mathrm{Cu} \mathrm{K} \alpha$ radiation $(\lambda=0.15405 \mathrm{~nm})$. The micrographs were obtained by scanning electron microscopy (NoVa Nano SEM 430). The Mössbauer spectrum was performed at room temperature, using a conventional Mössbauer spectrometer (Fast Com Tec PC-mossII), in constant acceleration mode. The $\gamma$-rays were provided by a ${ }^{57} \mathrm{Co}$ source in a rhodium matrix. Magnetization measurements were carried out with superconducting quantum interference device (MPMS-XL-7, Quantum Design) at room temperature.

\section{Results and Discussion}

3.1. XRD Patterns Analysis. Figure 1 shows the $\mathrm{XRD}$ patterns of $\mathrm{CoGd}_{x} \mathrm{Fe}_{2-x} \mathrm{O}_{4}(x=0,0.04,0.08)$ ferrites calcined at $800^{\circ} \mathrm{C}$ for $3 \mathrm{~h}$. The XRD patterns show that all the samples are single phase and all diffraction peaks can be indexed to the cubic spinel structure of $\mathrm{CoFe}_{2} \mathrm{O}_{4}$ (JCPDS card number 22-1086). No impurity peak was detected in these samples. Table 1 indicates that the lattice constant of Co ferrite substituting the $\mathrm{Gd}^{3+}$ sample is larger than that of the pure cobalt ferrite; it is due to the fact that the ionic radius of $\mathrm{Gd}^{3+}$ ions $(0.938 \AA)$ is larger than that of $\mathrm{Fe}^{3+}$ ions $(0.645 \AA)$ [8-11]. However, lattice parameter does not increase monotonously by increasing the gadolinium content, and it may be related to doping gadolinium having a larger radius in $\mathrm{CoFe}_{2} \mathrm{O}_{4}$ which leads to the lattice distortion [8].
The average crystallite size of the investigated samples is found to be around 31.6 to $55.6 \mathrm{~nm}$ by using Scherrer's formula $[10,12,13]$. The decreasing average crystallite size is with $\mathrm{Gd}^{3+}$ ions doping, which is in agreement with the results of literature [14-18]. They pointed out that the larger the bond energy of $\mathrm{Gd}^{3+}-\mathrm{O}^{2-}$ as compared to that of $\mathrm{Gd}^{3+}$ $\mathrm{O}^{2-}$, the more the energy needed to make $\mathrm{Gd}^{3+}$ ions enter into the lattice and form the bond of $\mathrm{RE}^{3+}-\mathrm{O}^{2-}$. Therefore, $\mathrm{Gd}^{3+}$ substituted ferrites have higher thermal stability relative to pure Co ferrite, and more energy is needed for the substituted samples to complete crystallization and grow grains.

The X-ray density was calculated using the following relation $[10,11,17]$ :

$$
\rho_{x}=\frac{8 M}{N a^{3}},
$$

where $M$ is relative molecular mass, $N$ is Avogadro's number, and " $a$ " is the lattice parameter. Table 1 shows that the Xray density is tending to increase with $\mathrm{Gd}^{3+}$ substitution. The atomic weight of $\mathrm{Gd}$ is greater than that of $\mathrm{Fe}$, so the relative molecular mass increases with the substitution of $\mathrm{Gd}^{3+}$ ions, and the lattice parameter of cobalt ferrite substituting the $\mathrm{Gd}^{3+}$ has no significant changes. So the increase in X-ray density is attributed to the fact that the relative molecular mass increases.

3.2. Structures and Grain Sizes. The SEM micrographs of $\mathrm{CoFe}_{2} \mathrm{O}_{4}$ ferrites annealed at $800^{\circ} \mathrm{C}$ for $3 \mathrm{~h}$ are shown in Figure 2. The distribution of grains with almost uniform size, well crystallized for the sample, can be observed. Figure 3 shows the histogram of grain size distribution of $\mathrm{CoGd}_{x} \mathrm{Fe}_{2-x} \mathrm{O}_{4}(x=0)$ ferrites. The average grain size estimated by a statistical method is approximately $96.26 \mathrm{~nm}$. The average grain size is slightly larger than the average crystallite size determined by XRD. This shows that every particle is formed by a number of crystallites [19-21].

The SEM micrographs of $\mathrm{CoGd}_{x} \mathrm{Fe}_{2-x} \mathrm{O}_{4}(x=0)$ are shown in Figure 4. The distribution of grains with almost uniform size, well crystallized for $\mathrm{CoGd}_{x} \mathrm{Fe}_{2-x} \mathrm{O}_{4}(x=0)$, can be observed. Some particles are agglomerated due to the presence of magnetic interactions among particles [14].

3.3. Mössbauer Spectroscopy. The Mössbauer spectra recorded at room temperature are shown in Figure 5 for $\mathrm{CoGd}_{x} \mathrm{Fe}_{2-x} \mathrm{O}_{4}(x=0,0.04,0.08)$. All samples have been analyzed using Mösswinn 3.0 program. For all samples, the spectra exhibit two normal Zeeman-split sextets due to $\mathrm{Fe}^{3+}$ at tetrahedral and octahedral sites, indicating the ferromagnetic behavior of the samples. The sextet with the larger isomer shift is assigned to the $\mathrm{Fe}^{3+}$ ions at $\mathrm{B}$ site, and the one with the smaller isomer shift is assumed to the $\mathrm{Fe}^{3+}$ ions occupying A site. Maybe it is due to the difference in $\mathrm{Fe}^{3+}-\mathrm{O}^{2-}$ internuclear separations. For the bond separation being larger for $\mathrm{B}$ site $\mathrm{Fe}^{3+}$ ions, in comparison with $\mathrm{A}$ site ions, smaller overlapping of orbits for $\mathrm{Fe}^{3+}$ and $\mathrm{O}^{2+}$ ions at $\mathrm{B}$ site occurs, resulting in smaller covalency and larger isomer shift for $\mathrm{B}$ site $\mathrm{Fe}^{3+}$ ions [22, 23]. It is evident from 


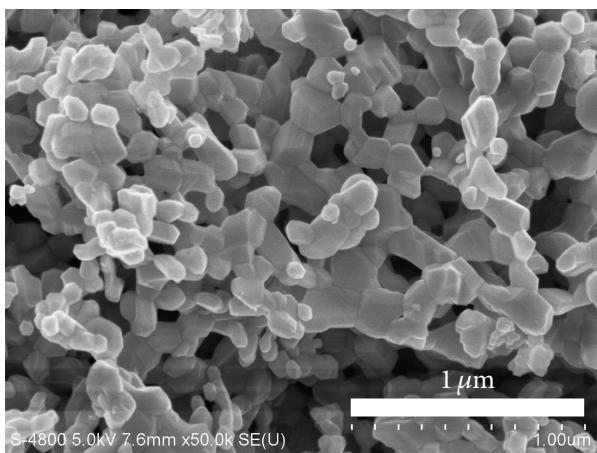

(a)

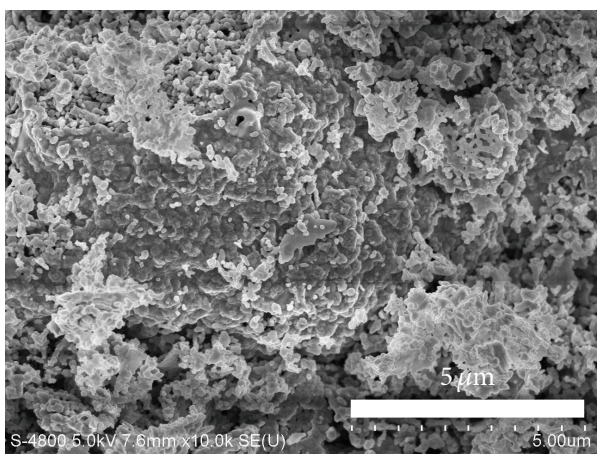

(c)

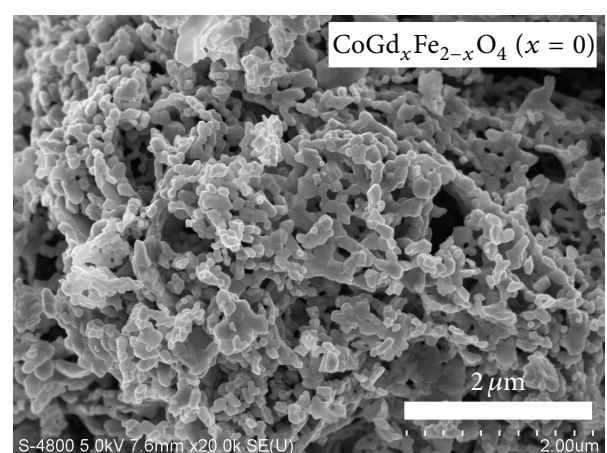

(b)

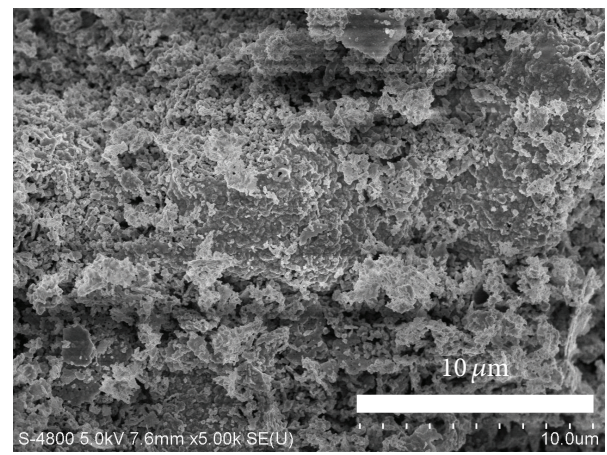

(d)

Figure 2: SEM micrographs depict $\mathrm{CoFe}_{2} \mathrm{O}_{4}$ ferrites with diameters of $1 \mu \mathrm{m}$ (a), $2 \mu \mathrm{m}$ (b), $5 \mu \mathrm{m}$ (c), and $10 \mu \mathrm{m}$ (d).

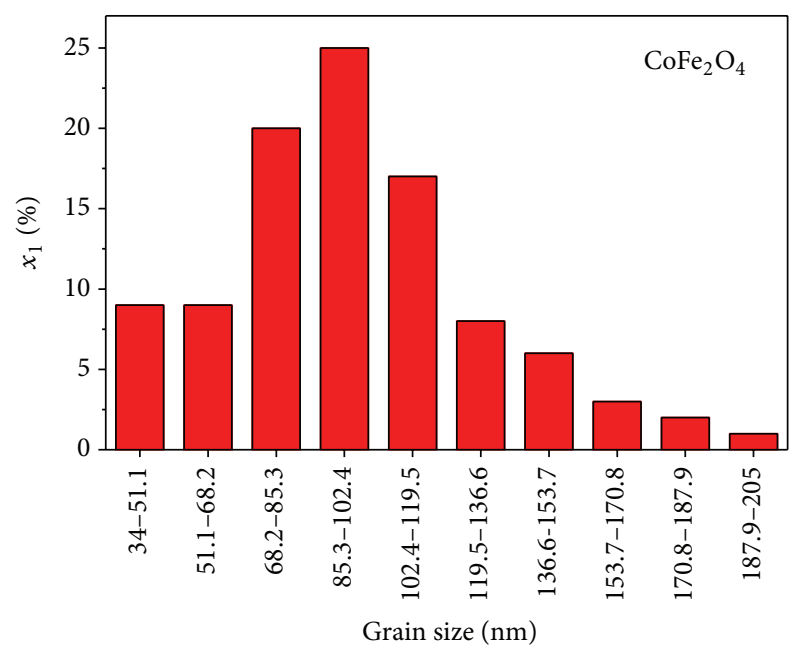

FIGURE 3: Histogram of grain size distribution for $\mathrm{CoFe}_{2} \mathrm{O}_{4}$ ferrites annealed at $800^{\circ} \mathrm{C}$.

Table 2 that isomer shifts values show very little change with $\mathrm{Gd}^{3+}$ substitution, which indicates that s electrons charge distribution of $\mathrm{Fe}^{3+}$ is not much influenced by $\mathrm{Gd}^{3+}$ substitution [23]. It is reported that the values of IS (Isomer shift) for $\mathrm{Fe}^{2+}$ ions lie in the range $0.6 \sim 1.7 \mathrm{~mm} / \mathrm{s}$, while for $\mathrm{Fe}^{3+}$ ions they lie in the range $0.1 \sim 0.5 \mathrm{~mm} / \mathrm{s}$ [24]. From

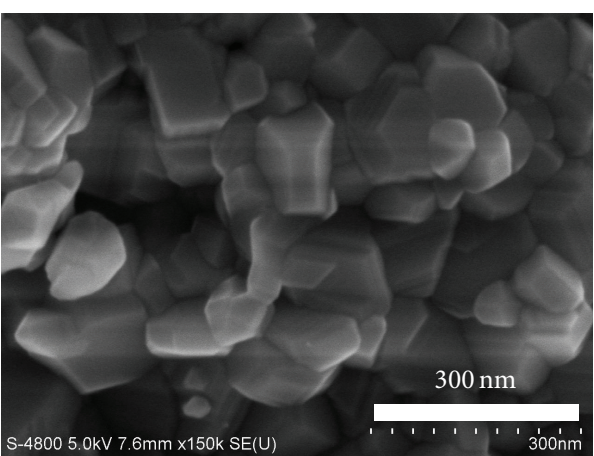

(a)

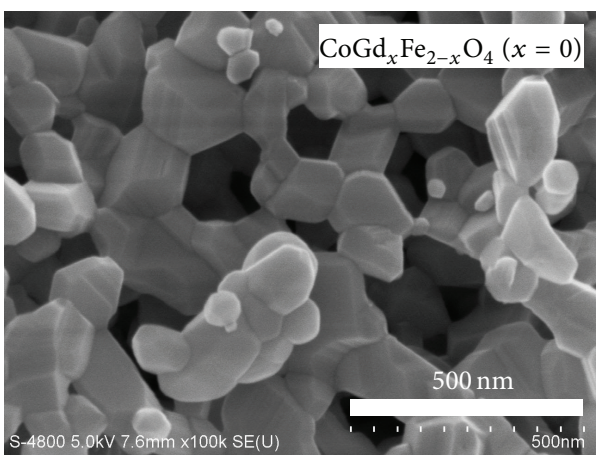

(b)

FIGURE 4: SEM micrographs of different part in $\mathrm{CoGd}_{x} \mathrm{Fe}_{2-x} \mathrm{O}_{4}(x=$ 0 ) ferrites with diameters of $300 \mathrm{~nm}$ (a) and $500 \mathrm{~nm}(\mathrm{~b})$. 

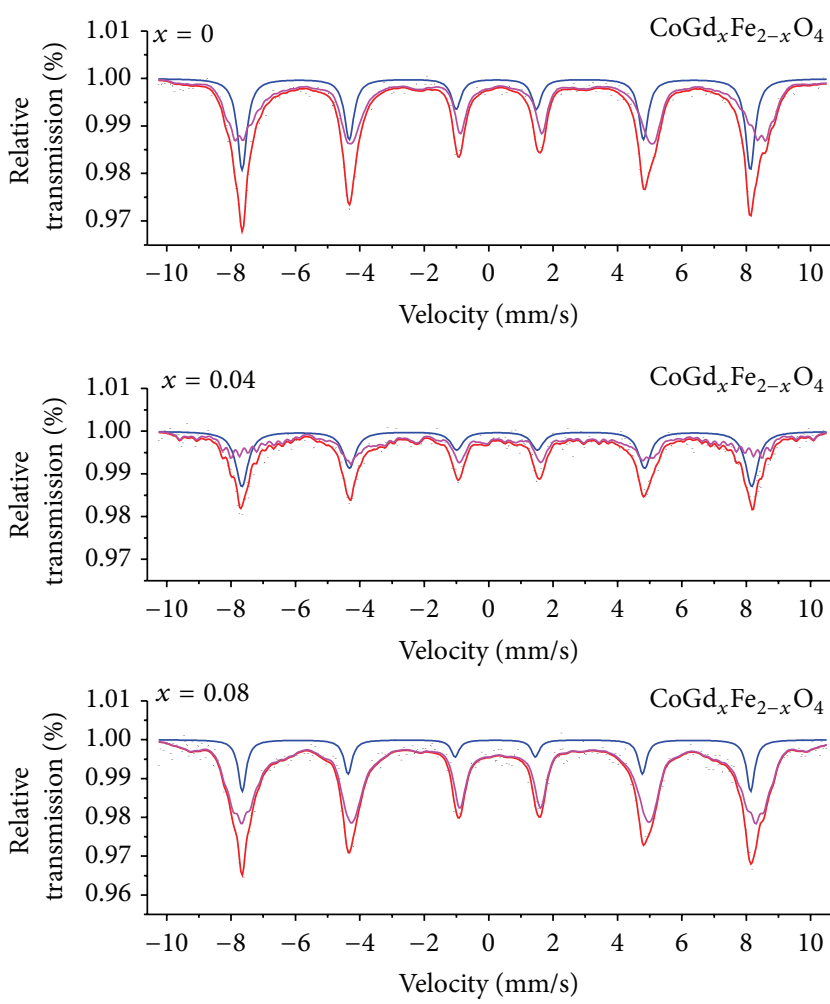

Figure 5: Room temperature Mössbauer spectra of $\mathrm{CoGd}_{x} \mathrm{Fe}_{2-x} \mathrm{O}_{4}$ $(x=0,0.04,0.08)$ ferrites annealed at $800^{\circ} \mathrm{C}$.

Table 2, values for IS in this paper indicate that iron is in $\mathrm{Fe}^{3+}$ state.

Table 3 shows that the values of magnetic hyperfine field at A site have no significant changes, and the magnetic hyperfine field at $\mathrm{B}$ site is tending to decrease by $\mathrm{Gd}^{3+}$ substitution. Maybe the $\mathrm{Fe}^{3+}$ ions of samples at lattice site are substituted by $\mathrm{Gd}^{3+}$ ions at $\mathrm{B}$ sites. Gd is the only RE element that has a Curie temperature $T_{C}(293.2 \mathrm{~K})$ close to room temperature $[16,25]$. Magnetic dipolar orientation of the RE exhibits a disordering form at room temperature; therefore, introducing rare-earth $\mathrm{Gd}^{3+}$ ions in $\mathrm{CoFe}_{2} \mathrm{O}_{4}$ seems like substituting magnetic $\mathrm{Fe}^{3+}$ ions (in octahedral $\mathrm{B}$ site of spinel lattice) by nonmagnetic atoms [8].

The value of quadrupole shift of the magnetic sextet is very small in all the samples indicating that the local symmetry of the ferrites obtained is close to cubic.

3.4. Magnetic Property of Particles. Figure 6 shows hysteresis loops of $\mathrm{CoGd}_{x} \mathrm{Fe}_{2-x} \mathrm{O}_{4}$ at room temperature. The magnetization of all samples nearly reaches saturation at the external field of 10000 Oe.

It is observed from Table 3 that saturation magnetization decreases as Gd content increases. The saturation magnetization could be expressed by means of the following relation [7]:

$$
\sigma_{s}=\frac{5585 \times n_{\mathrm{B}}}{M}
$$

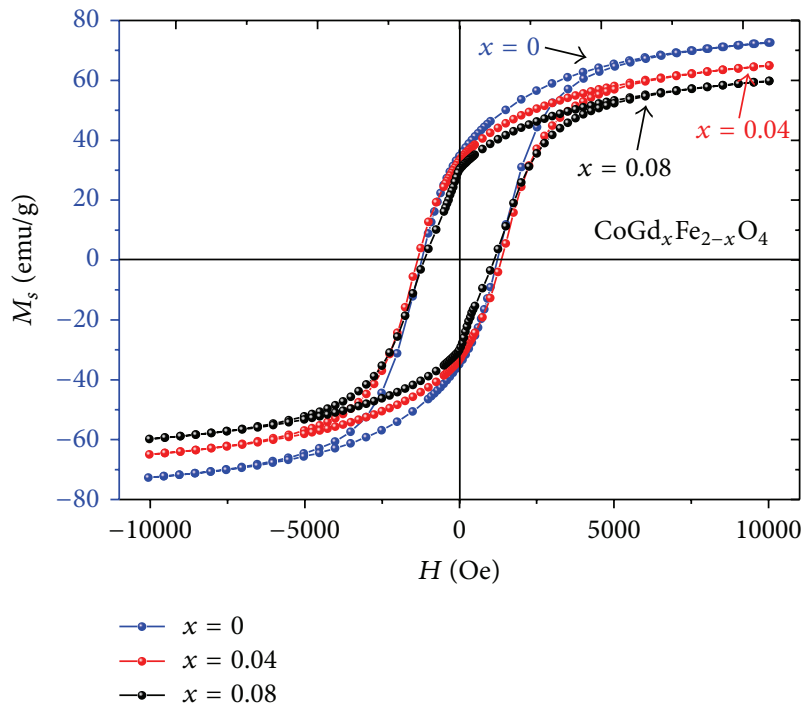

Figure 6: Room temperature hysteresis loops of $\operatorname{CoGd}_{x} \mathrm{Fe}_{2-x} \mathrm{O}_{4}$ $(x=0,0.04,0.08)$ annealed at $800^{\circ} \mathrm{C}$.

where $n_{\mathrm{B}}$ is the magnetic moment with Bohr magneton as the unit and $M$ is relative molecular mass. The relative molecular mass of $\mathrm{CoGd}_{x} \mathrm{Fe}_{2-x} \mathrm{O}_{4}$ increases as Gd content $x$ increases. The change of magnetic moment $n_{\mathrm{B}}$ can be explained with Néel's theory. The magnetic moment per ion for $\mathrm{Gd}^{3+}, \mathrm{Co}^{2+}$, and $\mathrm{Fe}^{3+}$ ions is $7.94 \mu_{\mathrm{B}}, 3 \mu_{\mathrm{B}}$, and $5 \mu_{\mathrm{B}}[15,16]$, respectively. As previously mentioned, magnetic dipolar orientation of the rare earth exhibits a disordering form at room temperature. Hence, in this paper, it may be reasonable that rare earth ions $\left(\mathrm{Gd}^{3+}\right)$ are considered as nonmagnetic ones at room temperature.

Since $\mathrm{Co}^{2+}$ prefer to occupy the octahedral site (B) in $\mathrm{CoFe}_{2} \mathrm{O}_{4}$ material of inverse spinel structure $[1,2], \mathrm{Gd}^{3+}$ ions occupy only the $\mathrm{B}$ sites for their large ion radii $[10,16]$. That is, the cation distribution is $(\mathrm{Fe})_{\mathrm{A}}\left[\mathrm{CoGd}_{x} \mathrm{Fe}_{1-x}\right]_{\mathrm{B}} \mathrm{O}_{4}$. According to Néel's two sublattice models of ferrimagnetism, the magnetic moment $\mathrm{n}_{B}$ is expressed as $[7,11]$

$$
n_{\mathrm{B}}=M_{\mathrm{B}}-M_{\mathrm{A}}=3+5(1-x)-5=3-5 x,
$$

where $M_{\mathrm{B}}$ and $M_{\mathrm{A}}$ are $\mathrm{B}$ and $\mathrm{A}$ sublattice magnetic moments, respectively. Figure 7 shows the change in experimental and theoretical magnetic moment with Gd content $x$.

From Figure 7, the experimental and theoretical magnetic moment decreases as Gd content $x$ increases, and according to relation (2) the theoretical saturation magnetization decreases with Gd content $x$. The variation of the experimental and theoretical saturation magnetization is in a good agreement with each other for all samples.

It is observed from Table 3 that the variation of coercivity with Gd content $x$ increases for $\mathrm{CoGd}_{x} \mathrm{Fe}_{2-x} \mathrm{O}_{4}$. It indicates that the coercivity of Co ferrite substituting the $\mathrm{Gd}^{3+}$ ions is larger than that of the pure cobalt ferrite. The phenomenon can be explained as follows. Like $\mathrm{Co}^{2+}$ ions, rare earth ions $\left(\mathrm{Gd}^{3+}\right)$ have stronger s-l coupling and weaker crystal field, so they have stronger magnetocrystalline anisotropy $[6,10$, 
TABLE 2: Mössbauer parameters of isomer shift (IS), quadrupole splitting (QS), magnetic hyperfine field $(H)$, linewidth $(\Gamma)$, and absorption area $\left(A_{0}\right)$ for $\mathrm{CoGd}_{x} \mathrm{Fe}_{2-x} \mathrm{O}_{4}(x=0,0.04,0.08)$ ferrites annealed at $800^{\circ} \mathrm{C}$.

\begin{tabular}{lcccccc}
\hline Sample $(x)$ & Component & IS $(\mathrm{mm} / \mathrm{s})$ & QS $(\mathrm{mm} / \mathrm{s})$ & $H(\mathrm{~T})$ & $\Gamma(\mathrm{mm} / \mathrm{s})$ & $A_{0}(\mathrm{~mm} / \mathrm{s})$ \\
\hline \multirow{2}{*}{0} & Sextet (A) & 0.237 & -0.004 & 48.946 & 0.360 & 32.4 \\
& Sextet (B) & 0.375 & -0.024 & 45.695 & 0.322 & 67.6 \\
\hline \multirow{2}{*}{0.04} & Sextet (A) & 0.256 & -0.006 & 49.105 & 0.462 & 38.3 \\
& Sextet (B) & 0.298 & -0.111 & 42.123 & 0.214 & 61.3 \\
\hline \multirow{2}{*}{0.08} & Sextet (A) & 0.223 & 0.037 & 48.964 & 0.304 & 14.3 \\
& Sextet (B) & 0.334 & -0.049 & 45.482 & 0.361 & 85.7 \\
\hline
\end{tabular}

TAble 3: Magnetic data for $\mathrm{CoGd}_{x} \mathrm{Fe}_{2-x} \mathrm{O}_{4}(x=0,0.04,0.08)$ ferrites annealed at $800^{\circ} \mathrm{C}$.

\begin{tabular}{lcccc}
\hline Sample $(x)$ & $M_{S}(\mathrm{emu} / \mathrm{g})$ & $H_{\mathrm{C}}(\mathrm{Oe})$ & $M_{r}(\mathrm{emu} / \mathrm{g})$ & $n_{\mathrm{B}}$ \\
\hline 0 & 72.58 & 1005.33 & 34.71 & 3.05 \\
0.04 & 65.00 & 1365.17 & 33.24 & 2.78 \\
0.08 & 59.77 & 1125.26 & 30.12 & 2.60 \\
\hline
\end{tabular}

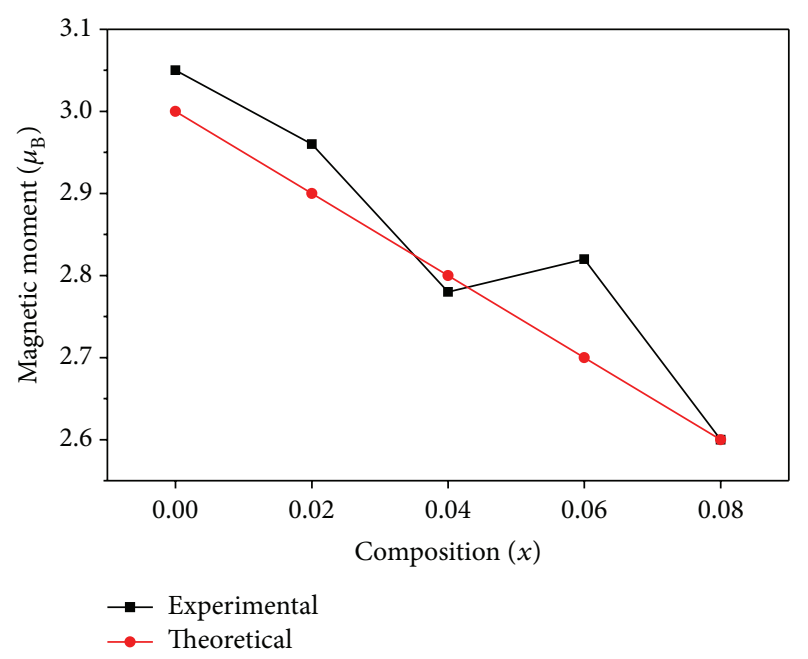

FIGURE 7: The variation in experimental and theoretical magnetic moment of $\mathrm{CoGd}_{x} \mathrm{Fe}_{2-x} \mathrm{O}_{4}$ ferrites with gadolinium content $x$.

$18,25,26]$. Furthermore, the radii of $\mathrm{Gd}^{3+}$ ions are larger than that of $\mathrm{Fe}^{3+}$ ions, and the symmetry of crystal will be decreased after the sample was substituted by $\mathrm{Gd}^{3+}$ ions and hence may distort the lattice or crystalline field and generate an internal stress $[13,14]$. Moreover, it is known that the grain boundary increases with decreasing crystallite size. In this study, Gd substituted ferrites have a decrease in crystallite size with the substitution of $\mathrm{Gd}^{3+}$ ions. The area of disordered arrangement for ions on grain boundaries may fix and hinder the domain walls motion; thus the coercivity of the samples increases with $\mathrm{Gd}^{3+}$ ions substituted cobalt ferrite [14]. However the coercivity does not increase monotonously by increasing the gadolinium content, and it may be related to the coercivity which is influenced by many factors, such as crystallinity, microstrain, magnetic particle morphology and size distribution, anisotropy, and magnetic domain size $[14,27,28]$.

\section{Conclusion}

The analysis of XRD patterns reveals the formation of single-phase cubic spinel structure for $\mathrm{CoGd}_{x} \mathrm{Fe}_{2-x} \mathrm{O}_{4}(x=$ $0,0.04,0.08)$ ferrite annealed at $800^{\circ} \mathrm{C}$. The increase in lattice constant is due to replacement of smaller $\mathrm{Fe}^{3+}$ ions by larger $\mathrm{Gd}^{3+}$ ions. SEM results indicate the distribution of grains and morphology of the samples. Some particles are agglomerated due to the presence of magnetic interactions among particles. The ferrite powers are nanoparticles. Room temperature Mössbauer spectra of $\mathrm{CoGd}_{x} \mathrm{Fe}_{2-x} \mathrm{O}_{4}(x=0,0.04,0.08)$ ferrites are two normal Zeeman-split sextets. It displays ferrimagnetic behavior for the samples. The saturation magnetization decreases and the coercivity increases with the substitution of $\mathrm{Gd}^{3+}$ ions. The decreases of the saturation magnetization can be explained with Néel's theory. The variation of coercivity is attributed to magneto-crystalline anisotropy, microstrain, and grain boundary.

\section{Conflict of Interests}

The authors declared that they have no conflict of interests to this work.

\section{Acknowledgments}

This work was financially supported by the National Natural Science Foundation of China (no. 11364004, 11164002) and Innovation Project of Guangxi Graduate Education under Grant (no. 2010106020702M47).

\section{References}

[1] B. Babić-Stojić, V. Jokanović, D. Milivojević et al., "Magnetic and structural studies of $\mathrm{CoFe}_{2} \mathrm{O}_{4}$ nanoparticles suspended in an organic liquid," Journal of Nanomaterials, vol. 2013, Article ID 741036, 9 pages, 2013.

[2] S. Amiri and H. Shokrollahi, "The role of cobalt ferrite magnetic nanoparticles in medical science," Materials Science and Engineering C, vol. 33, no. 1, pp. 1-8, 2013. 
[3] N. Sanpo, C. C. Berndt, C. Wen, and J. Wang, "Transition metal-substituted cobalt ferrite nanoparticles for biomedical applications," Acta Biomaterialia, vol. 9, no. 3, pp. 5830-5837, 2013.

[4] C. H. Chia, S. Zakaria, M. Yusoff et al., "Size and crystallinitydependent magnetic properties of $\mathrm{CoFe}_{2} \mathrm{O}_{4}$ nanocrystals," Ceramics International, vol. 36, no. 2, pp. 605-609, 2010.

[5] M. M. Eltabey, A. M. Massoud, and C. Radu, "Microstructure and superparamagnetic properties of $\mathrm{Mg}-\mathrm{Ni}-\mathrm{Cd}$ ferrites nanoparticles," Journal of Nanomaterials, vol. 2014, Article ID 492832, 7 pages, 2014.

[6] G. Dascalu, T. Popescu, M. Feder, and O. F. Caltun, "Structural, electric and magnetic properties of $\mathrm{CoFe}_{1.8} \mathrm{RE}_{0.2} \mathrm{O}_{4}(\mathrm{RE}=\mathrm{Dy}$, Gd, La) bulk materials," Journal of Magnetism and Magnetic Materials, vol. 333, pp. 69-74, 2013.

[7] S. Kanagesan, M. Hashim, S. Tamilselvan, N. B. Alitheen, I. Ismail, and G. Bahmanrokh, "Cytotoxic effect of nanocrystalline $\mathrm{MgFe}_{2} \mathrm{O}_{4}$ particles for cancer cure," Journal of Nanomaterials, vol. 2013, Article ID 865024, 8 pages, 2013.

[8] J. Peng, M. Hojamberdiev, Y. Xu, B. Cao, J. Wang, and $\mathrm{H}$. Wu, "Hydrothermal synthesis and magnetic properties of gadolinium-doped $\mathrm{CoFe}_{2} \mathrm{O}_{4}$ nanoparticles," Journal of Magnetism and Magnetic Materials, vol. 323, no. 1, pp. 133-138, 2011.

[9] A. Rana, O. P. Thakur, and V. Kumar, "Effect of Gd ${ }^{3+}$ substitution on dielectric properties of nano cobalt ferrite," Materials Letters, vol. 65, no. 19-20, pp. 3191-3192, 2011.

[10] S. Amiri and H. Shokrollahi, "Magnetic and structural properties of $\mathrm{RE}$ doped co-ferrite $(\mathrm{RE}=\mathrm{Nd}, \mathrm{Eu}$, and $\mathrm{Gd})$ nanoparticles synthesized by co-precipitation," Journal of Magnetism and Magnetic Materials, vol. 345, pp. 18-23, 2013.

[11] J. Chand, G. Kumar, P. Kumar, S. K. Sharma, M. Knobel, and M. Singh, "Effect of $\mathrm{Gd}^{3+}$ doping on magnetic, electric and dielectric properties of $\mathrm{MgGd}_{\mathrm{x}} \mathrm{Fe}_{2-\mathrm{x}} \mathrm{O}_{4}$ ferrites processed by solid state reaction technique," Journal of Alloys and Compounds, vol. 509, no. 40, pp. 9638-9644, 2011.

[12] M. M. Rashad, R. M. Mohamed, and H. El-Shall, "Magnetic properties of nanocrystalline Sm-substituted $\mathrm{CoFe}_{2} \mathrm{O}_{4}$ synthesized by citrate precursor method," Journal of Materials Processing Technology, vol. 198, no. 1-3, pp. 139-146, 2008.

[13] L. Guo, X. Shen, F. Song, L. Lin, and Y. Zhu, "Structure and magnetic property of $\mathrm{CoFe}_{2-x} \mathrm{Sm}_{x} \mathrm{O}_{4}(x=0-0.2)$ nanofibers prepared by sol-gel route," Materials Chemistry and Physics, vol. 129, no. 3, pp. 943-947, 2011.

[14] J. Jiang and Y.-M. Yang, "Effect of Gd substitution on structural and magnetic properties of $\mathrm{Zn}-\mathrm{Cu}-\mathrm{Cr}$ ferrites prepared by novel rheological technique," Materials Science and Technology, vol. 25, no. 3, pp. 415-418, 2009.

[15] Y. Y. Meng, Z. W. Liu, H. C. Dai et al., "Structure and magnetic properties of $\mathrm{Mn}(\mathrm{Zn}) \mathrm{Fe}_{2-x} \mathrm{RE}_{x} \mathrm{O}_{4}$ ferrite nano-powders synthesized by co-precipitation and refluxing method," Powder Technology, vol. 229, pp. 270-275, 2012.

[16] L. Zhao, Y. Cui, H. Yang, L. Yu, W. Jin, and S. Feng, "The magnetic properties of $\mathrm{Ni}_{0.7} \mathrm{Mn}_{0.3} \mathrm{Gd}_{x} \mathrm{Fe}_{2-x} \mathrm{O}_{4}$ ferrite," Materials Letters, vol. 60, no. 1, pp. 104-108, 2006.

[17] M. Asif Iqbal, M.-U. Islam, M. N. Ashiq, I. Ali, A. Iftikhar, and H. M. Khan, "Effect of Gd-substitiution on physical and magnetic properties of $\mathrm{Li}_{1.2} \mathrm{Mg}_{0.4} \mathrm{Gd}_{\mathrm{x}} \mathrm{Fe}_{(2-\mathrm{x})} \mathrm{O}_{4}$ ferrites," Journal of Alloys and Compounds, vol. 579, pp. 181-186, 2013.

[18] R. N. Panda, J. C. Shih, and T. S. Chin, "Magnetic properties of nano-crystalline Gd- or Pr-substituted $\mathrm{CoFe}_{2} \mathrm{O}_{4}$ synthesized by the citrate precursor technique," Journal of Magnetism and Magnetic Materials, vol. 257, no. 1, pp. 79-86, 2003.
[19] M. M. Ruiz, J. L. Mietta, P. Soledad Antonel, O. E. Pérez, R. Martín Negri, and G. Jorge, "Structural and magnetic properties of $\mathrm{Fe}_{2-x} \mathrm{CoSm}_{x} \mathrm{O}_{4}$-nanoparticles and $\mathrm{Fe}_{2-x} \operatorname{CoSm}_{x} \mathrm{O}_{4}$-PDMS magnetoelastomers as a function of Sm content," Journal of Magnetism and Magnetic Materials, vol. 327, pp. 11-19, 2013.

[20] L. B. Tahar, L. S. Smiri, M. Artus et al., "Characterization and magnetic properties of Sm- and Gd-substituted $\mathrm{CoFe}_{2} \mathrm{O}_{4}$ nanoparticles prepared by forced hydrolysis in polyol," Materials Research Bulletin, vol. 42, no. 11, pp. 1888-1896, 2007.

[21] A. I. Borhan, T. Slatineanu, A. R. Iordan, and M. N. Palamaru, "Influence of chromium ion substitution on the structure and properties of zinc ferrite synthesized by the sol-gel autocombustion method," Polyhedron, vol. 56, pp. 82-89, 2013.

[22] J. Lin, Y. He, Q. Lin, R. Wang, and H. Chen, "Microstructural and Mössbauer spectroscopy studies of $\mathrm{Mg}_{1-x} \mathrm{Zn}_{x} \mathrm{Fe}_{2} \mathrm{O}_{4}(x=$ 0.5, 0.7) nanoparticles," Journal of Spectroscopy, vol. 2014, Article ID 540319, 5 pages, 2014.

[23] S. S. R. Inbanathan, V. Vaithyanathan, J. Arout Chelvane, G. Markandeyulu, and K. Kamala Bharathi, "Mössbauer studies and enhanced electrical properties of $\mathrm{R}(\mathrm{R}=\mathrm{Sm}, \mathrm{Gd}$ and $\mathrm{Dy})$ doped Ni ferrite," Journal of Magnetism and Magnetic Materials, vol. 353, pp. 41-46, 2014.

[24] S. Kumar, A. M. M. Farea, K. M. Batoo et al., "Mössbauer studies of $\mathrm{Co}_{0.5} \mathrm{Cd}_{x} \mathrm{Fe}_{2.5-x} \mathrm{O}_{4}(0.0-0.5)$ ferrite," Physica B, vol. 403, pp. 3604-3607, 2008.

[25] T. Jiao, Y. Wang, Q. Zhang et al., "Self-assembly and headgroup effect in nanostructured organogels via cationic amphiphilegraphene oxide composites," PLoS ONE, vol. 9, no. 7, Article ID e101620, 2014.

[26] Q. Lin, Z. Ye, C. Lei, H. Huang, J. Xu, and Y. He, "Microstructure and magnetic research of NiCuZn ferrite by Co, Bi compound doped," Materials Research Innovations, vol. 17, no. s1, pp. s287s291, 2013.

[27] S. H. Hosseini and A. Asadnia, "Synthesis, characterization, and microwave-absorbing properties of polypyrrole/ $\mathrm{MnFe}_{2} \mathrm{O}_{4}$ nanocomposite," Journal of Nanomaterials, vol. 2012, Article ID 198973, 6 pages, 2012.

[28] T. Jiao, Q. Huang, Q. Zhang, D. Xiao, J. Zhou, and F. Gao, "Selfassembly of organogels via new luminol imide derivatives: diverse nanostructures and substituent chain effect," Nanoscale Research Letters, vol. 8, article 278, 2013. 

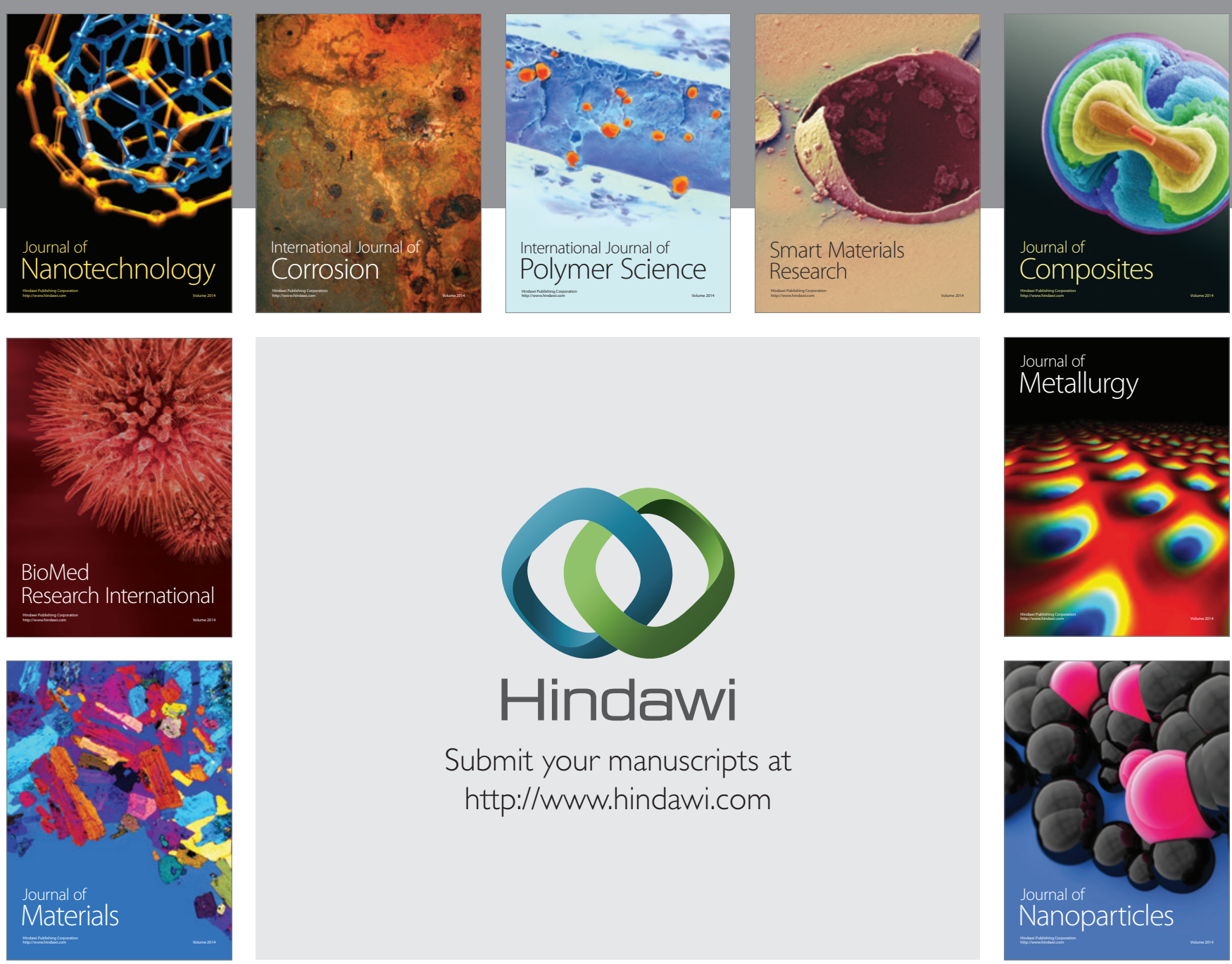

Submit your manuscripts at http://www.hindawi.com
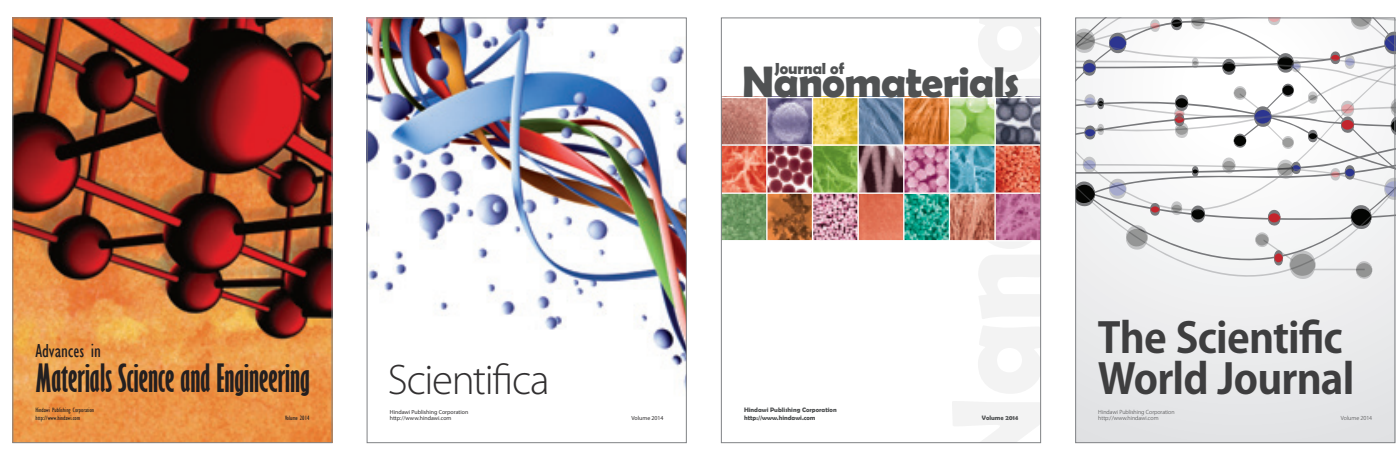

\section{The Scientific World Journal}
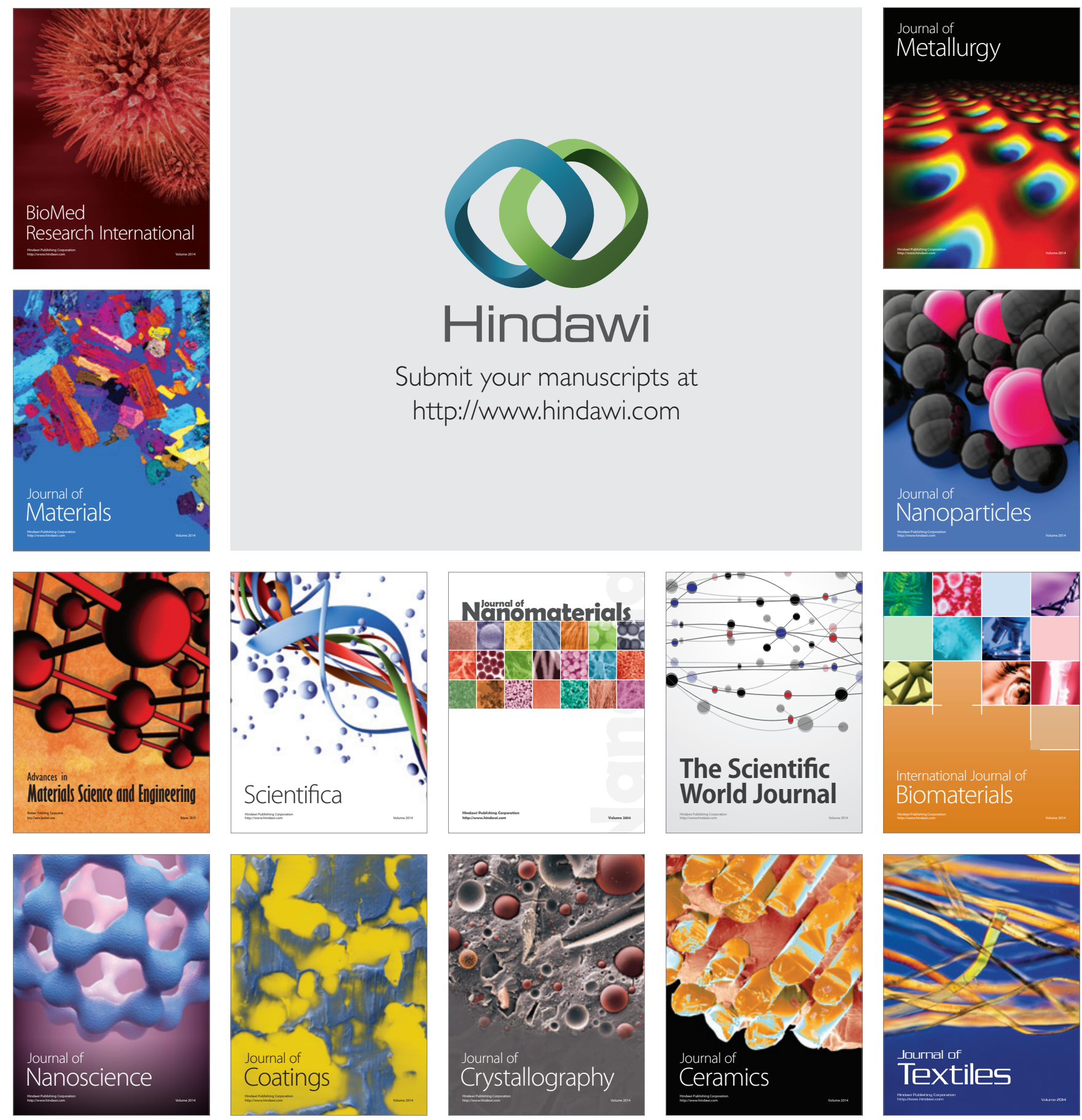